\title{
Research on Wuyi County Road Traffic Leading Rural Revitalization Practice Based on Life Quality Evaluation Index
}

\author{
Jiao Huijing ${ }^{1}$, Wang Jin' ${ }^{1}$, and Yang Xuefeng ${ }^{1, *}$ \\ ${ }^{1}$ Ordos Institute of Technology, Kangbashi, Ordos, China
}

\begin{abstract}
In order to study the influence and development of transportation on rural revitalization in suburban counties in southern China, Xinzhai Town, Wuyi County, Zhejiang Province, was selected as the research object, and field interviews and data collection were used to analyze the practical impact and significance of road traffic development on rural revitalization.
\end{abstract}

\section{Preface}

Before the reform and opening up, Wuyi County has an area of only 0.48 square kilometers and a permanent population of only 22900 people. At that time, the streets of Wuyi County were lined with simple and low houses, and the streets were all built with stones and pebbles. But with the War of Resistance against, many times by the Japanese bombing, burning, so that the street everywhere. Wuyi County at that time although a county, but more like a market town.

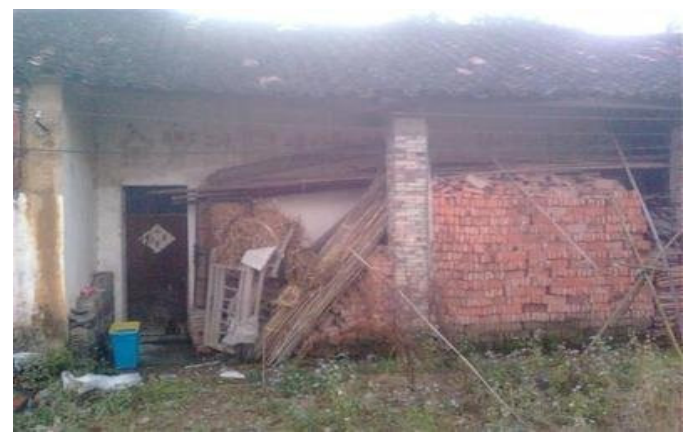

Fig 1. Wuyi Town before Reform and opening up

In the late autumn of 1993, the bus station was taken as the starting point and extended eastward to the railway station under planning. Since the 1980 s, Wuyi has experienced four large-scale urban transformation. The area of Wuyi Town has expanded from 0.48 square kilometers to 34.23 square kilometers, and the resident population has expanded from 22900 to 197100 . With the continuous development of social economy, building roads and expanding traffic have become important reform contents. Rural roads are the most important means of transportation in rural areas. In the implementation of the rural revitalization strategy, rural roads play an important role in leading and supporting services.[1]. Due to historical and practical reasons, the strategy of rural revitalization is the development focus of our country [2]. With the continuous development of social economy, transportation occupies a very important position in whether the social economy can develop more efficiently. It can be said that transportation is promoting social and economic development.

With the continuous development of social economy, transportation plays a very important role in the more efficient development of social economy. It can be said that transportation is promoting social and economic development

There is a long-term equilibrium relationship between Zhejiang's economic development and transportation, and there is a positive correlation between Zhejiang's economic growth and transportation development [3]. Wuyi County, located in the middle of Zhejiang Province, has abundant natural resources, high-quality geographical environment, and suitable climate; it is adjacent to Jinhua in the north, Lishui in the south, Yongkang in the east, and Suichang in the west.

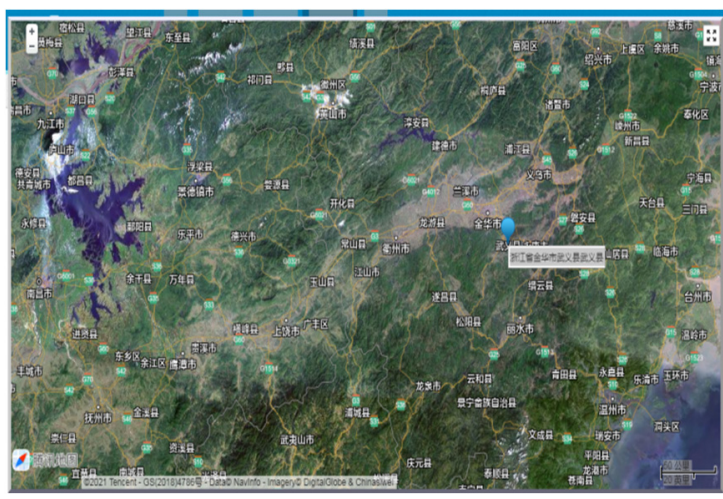

Fig 2. Location satellite map of Wuyi County

Wuyi County here geographical advantages, historical advantages, agriural tourism advantages are very prominent, road traffic development will change here to achieve rural revitalization, and Wuyi County as a suburban county in the southern region, rural 
revitalization has a certain demonstration. Therefore, this paper selects Wuyi County, Jinhua City, Zhejiang Province as an example to study the application and function of road traffic to rural revitalization and development, draw research conclusions, and give specific suestions for rural traffic development.

\section{Wuyi County Road Traffic Development}

The development of economy can not be separated from transportation. Only by opening the road and realizing the two-way transportation exchange from inside to outside and from outside can we open the door and meet the new economy. With the concept of "want to be rich, build roads first, build roads first ," and" highway links," Wuyi Xing", Wuyi County firmly grasps the policy of "four self-projects " (self-loan, self-construction, self-charge, self-repayment), and implements the" six unified and five packages" (unified standards, unified design, unified bidding, unified supervision, unified management, unified coordination; time limit, package cost, package requisition and relocation, package quality, package management), and carries out targeted rural revitalization plans for 7 towns and 16 townships in Wuyi County. After 70 years of continuous development, as of 2018, Wuyi County highway increased from the first one to 401, including 1 highway ,2 roads, 2 provincial roads, 3 special roads, 36 county roads.

Table1. Development of Highway from Eleventh Five-Year Plan to Thirteenth Five-Year Plan

\begin{tabular}{|c|c|c|c|}
\hline Indicators & Eleventh Five-Year & 12th Five-Year Plan & 13th Five-Year Plan \\
\hline $\begin{array}{c}\text { Total road network } \\
\text { mileage }\end{array}$ & 11512 kilometres & 12431 kilometres & 14369 \\
\hline Highway & 310 kilometres & 354 kilometres & 446 \\
\hline $\begin{array}{c}\text { Provincial road } \\
\text { network in general }\end{array}$ & 766 kilometres & 1115 kilometres & 580 \\
\hline $\begin{array}{c}\text { Total mileage of roads } \\
\text { above Grade II }\end{array}$ & 1860 kilometres & 2228 kilometres & 2845 \\
\hline Rural road mileage & 10203 kilometres & 11316 kilometres & 2845 \\
\hline $\begin{array}{c}\text { Highway grade } \\
\text { passenger station }\end{array}$ & 31 & 38 & \\
\hline
\end{tabular}

From the initial single mode of transportation to the construction of interconnected comprehensive transportation network, Wuyi County has played an important and irreplaceable role in economic development.

In the aspect of expressway, we should focus on building the main axis of Jinyi metropolitan area development, guide and perfect the adjustment of industrial and urban spatial layout, and promote the interconnection between cities. Considering the layout of expressway network and the matching of traffic demand, the expressway planning forms a "one circle, six shots and three links" expressway network with a total mileage of 446 kilometers. Long-term planning Yiwu Shugang Expressway north extension, Yijin thoroughfare. On the highway (including Hangzhou Jinqu Expressway Jinhua
Branch), Jinqianhuang Expressway, Wusonglong Expressway.

With regard to the provincial roads of ordinary, according to the principles of adapting to the requirements of economic and social development, coordinating with the urban layout and the comprehensive transportation network layout of Jinyi metropolitan area, and saving and intensive utilization of resources, the provincial roads of ordinary countries in our city form a "seven vertical and eight horizontal" layout with a total planned mileage of about $1890 \mathrm{~km}$, of which the ordinary roads are about $580 \mathrm{~km}$ and the ordinary provincial roads are about $131 \mathrm{~km}$.

A Circle : Jinyi Metropolitan Expressway Closed Circle

Shooting : Hangzhou-Shanghai - - North Section of Yiwu, Jinqu Expressway

Shaoxing, Ningbo direction - - Yongiin Expressway east of Yiwu section Hangzhou, Linan direction - - Linjin Expressway

Quzhou, Jiangxi - - - Hangzhou Jingu Expressway west section of Wucheng Taizhou, Xianju direction -- Taijin Expressway

Direction of Wenzhou and Lishui -- South Section of Yongkang of Jinliwen Expressway

Sanlian : Yongin Expressway fu Cun Yi Wu Oingkou, Jin Hua section of Zhuyong Expressway, National Highway, Planning S208 Provincial Road, Planning S209 Provincial Road, Planning Provincial Road, Planning S215 Provincial Road, Planning Provincial Road, Planning Provincial Road, Planning S221 Provincial Road

National : G527, G351, G330, Provincial, Provincial, Planning 5317 Provincial, Planning Provincial, Planning 5319 Provincial, Planning Provincial

Fig 3. Details of the layout of the national and provincial highways

On important county roads, due to the adjustment of the provincial network, some of the original provincial roads were adjusted to major county roads, forming the "15th Union ".They are Baitang Downline, Jinlan North Line, Jiangtang-Luodian Highway, Old Provincial Highway 03, Jinyi Expressway, Lanxi-Jinyi Metropolitan New Area Highway (Baiya Line), Jinhua emerging industry cluster area from Lanxi Shanghua to Wu Chenglangya Highway, Xitianfan Expressway Connecting Line (Yongwu Third Line), Yipu Second Line, Yidong Highway, Old 39 Provincial Highway, Dongyong Second Line, Dongyang-Pan'an Yaochuan Highway, Dongyong First Line, Yongwu Second Line, total mileage 510 Kilometers.

There is no end to building roads, and there is a way to revitalize them. Transportation is the leading and basic industry in the development of economy and society, and rural transportation is not only the important foundation for farmers to travel safely and conveniently, to promote the development of rural industry and economic growth, but also the premise for rural residents to enjoy basic public services such as education and medical treatment. It is also the internal requirement to promote clean and tidy village appearance, civilized countryside style and realize beautiful countryside[4].

With the continuous development of road traffic, the road is wider and flatter than before. Wuyi County in all directions, no longer limited to a single road. And the increase of roads provides greater convenience for vehicles, others in and out. At the same time, Wuyi County highway mileage also increased. 
Table2. . Miles in Wuyi County ,2015-2019

\begin{tabular}{|l|c|l|}
\hline Wuyi County & Kilometres $(\mathrm{km})$ & $\begin{array}{l}\text { Highway mileage } \\
(\mathrm{km})\end{array}$ \\
\hline 2015 & 1378 & 26 \\
\hline 2016 & 1379 & 26 \\
\hline 2017 & 1414 & 26 \\
\hline 2018 & 1424 & 26 \\
\hline 2019 & 1424 & 26 \\
\hline
\end{tabular}

According to the data in the table, the number of kilometers in Wuyi County increased year by year in 2015-2018, and tended to stabilize in 2018-2019. Thus, the increase in road traffic has increased the mileage in the county. Expanded the people's travel radius, increased the feasibility and convenience of people to other areas.

\section{Influence of Road Traffic Development in Wuyi County}

\subsection{Economic implications of road traffic}

The increase of road traffic and the facilitation of transportation have promoted the development of agriural products transportation and tourism in Wuyi County, and increased the passenger and cargo transportation volume of railway and highway in Wuyi County.

Table3. Railway passenger and cargo capacity, Wuyi County ,2015-2019

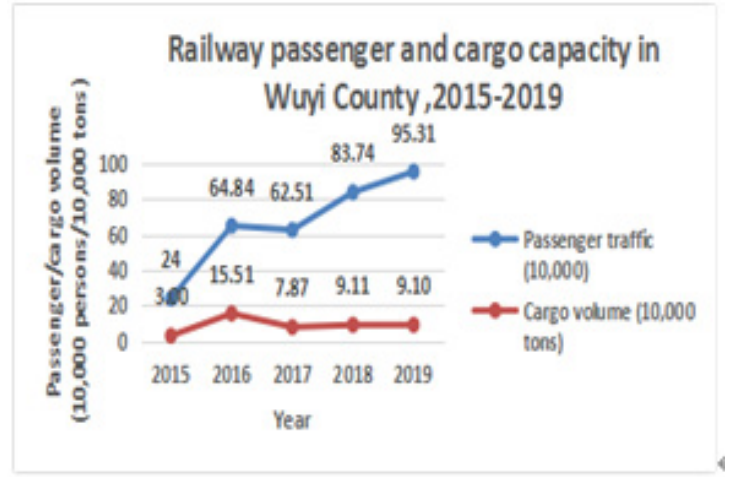

Table4. Road passenger and cargo capacity, Wuyi County ,2015-2019

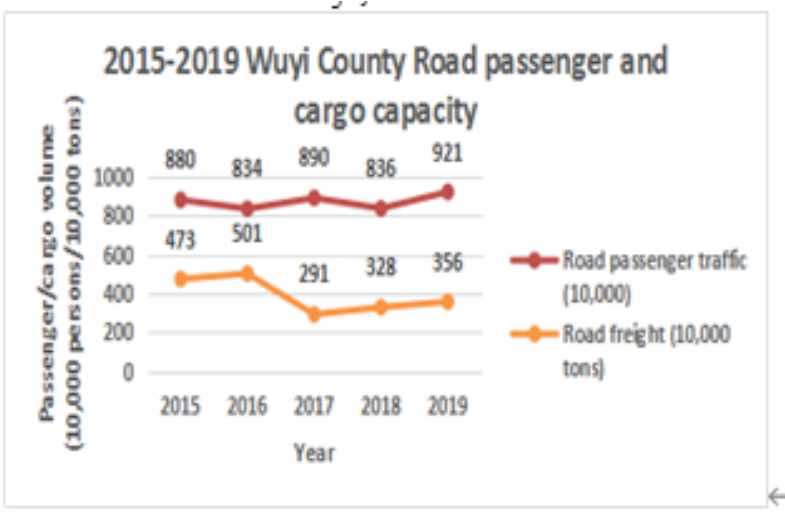

From the data statistics, from 2015 to 2019, Wuyi County railway, road passenger and cargo transport volume has declined a little in some years, but the overall growth state, which also reflects the increase of population flow in Wuyi County to a certain extent. With the increase of cargo transport, the people's gross domestic product has also increased. By 2019, the county's gross domestic product (GDP) reached 21.655 billion yuan. Among them: primary industry added value 200 million yuan; secondary industry added value 610 million yuan; tertiary industry added value 900 million yuan.

\subsection{Impact of road traffic on business activities}

After 70 years of continuous development, as of 2018 , Wuyi County highway increased from the first one to 401, including 1 highway, 2 roads , 2 provincial roads , 3 special roads , 36 county roads. The rapid increase in road traffic has led to exchanges and counication between Wuyi County and various cities in Zhejiang Province. With the continuous expansion of roads, cities, districts and townships are closely combined to promote the development of transportation, warehousing and postal services in Wuyi County.

Table5. .Total GDP of transportation, storage and postal services in Wuyi County ,2015-2019

Gross production value of transportation, storage and postal industry
\begin{tabular}{|l|l|}
2015 & 453.83 million yuan \\
\hline 2016 & 493.05 million yuan \\
\hline 2017 & 52058 million yuan \\
\hline 2018 & 543.2 million yuan \\
\hline 2019 & 700 million yuan
\end{tabular}

Through the analysis of the research data in Table 1, the GDP of transportation, storage and postal industry in Wuyi County increased year by year between 2015 and 2019. The gross domestic product of the transportation, storage and postal industries increased between 2015 and 2018, but all fell within 40 million yuan. Therefore, although the four years have increased, but not very volatile, but until 2018-2019, the transport, warehousing and postal industry's GDP reached a qualitative leap, the GDP reached 700 million yuan. However ,2018 happened to be a year when Wuyi County built 401 roads. It can be seen that transportation plays a vital role in promoting the economy and promoting rural revitalization, and has a certain influence.

Eco-agriural tourism is an important way to develop countryside[5].Wuyi Hot Spring, for example, has a solid foundation for the development of the hot spring industry. Wuyi Hot Spring Tourism Resort is the province's first provincial tourist resort named after hot springs, and the province's first hot spring class A scenic spot. Adhere to the "full speed advance ", with large projects to promote the development of tourism. Link tourism and all aspects together, better promote the development of tourism. "Tourism + Sports ": relying on Wuyi National Car Rally, National Bridge Competition and other brand events to 
attract tourists, this year's newly opened Dadoushan flying base is more popular, full of tourists;" Tourism + Industry": Shoushanu pharmaceutical industry as the representative of traditional Chinese medicine health ure tourism has been steadily developed;" Tourism + Agriure ": Dabojin Eco-agriure leisure and sightseeing manor, thousands of acres of rock bamboo sea leisure and sightseeing park, camel Kowloon black tea ural park and other modern agriural parks become popular attractions.

\subsection{Impact of road traffic on education}

In the 1960s, Mud house, mud wall, broken class table, oil wax paper has been synonymous with all schools in Wuyi County. Without proper classrooms, proper equipment, The children in the village can only go to school in the village. Although you can go to school, But the conditions for school are also very diffi. Students need to walk several kilometers every day to get to the school. They used simple wooden tables and chairs to teach in low mud-tile and wooden classrooms. The teachers were insufficient. This was the Hushan Primary School at the time. With the development of transportation and the change of school buildings, it has promoted the development of education. After the 13th Five-Year Plan, Wuyi County to the provincial basic education key counties as the top priority of education development, Speed up the construction of projects to promote the balanced development of high-quality education. Ten new schools, including Hushan Primary School, have been built and put into use. The campus of Hushan Primary School is from Hushan Shangjie 184, Hushan Shangjie 137, Beiling Campus to 99 Rixi North Road now, Four landmarks carry the vicissitudes of life in the past 70 years. Now Hushan Primary School near residential areas, with brand-new tables and chairs, beautiful campus environment, strong teachers. The constant change of school symbolizes the continuous development of education, Witnessed the process of road traffic promoting educational progress.

\subsection{Impact of road traffic on people's lives}

The development of road traffic has led to the development of agriural products and tourism in Wuyi County. With the gradual progress of various industries on the right track, the income level of the people has to be improved accordingly. The rural construction under the new requirements of rural revitalization planning strategy should not only fully reflect the characteristics of rural development in different regions, but also clarify the key points of rural construction in different regions[6]. Through a sample survey of households in Wuyi County, Survey results show that all residents of Wuyi County per capita disposable income of 26140 yuan, The increase was 7.6 per cent. The county's rural residents per capita disposable income of 14834 yuan, Increase by 8.5 per cent; The per capita disposable income of urban residents is 32894 yuan, The increase was 7.1 per cent. Rural residents per capita expenses of 11512 yuan, 9.8 per cent increase; Urban resident per capita consumption expenditure of 24104 yuan, An increase of 7.9 per cent.

With the development of the garden, rural tourism can fully show the new economy. With the address of the garden in Wuyi County, Datian Township Wanpu Village, this is a very small village, less than 200 villagers. The owner is a gentle middle-aged man, named Dai Jun, bowl shop village people, young to go out, engaged in decoration industry, has done a variety of high-grade hotel decoration design projects in Beijing, Shanghai, Guangzhou and other places, in the industry quite successful, rich income. But the more rolling in the flood of the city, the more diffi to forget the heart of a wisp of thought. In recent years, Wuyi County in his hometown has vigorously developed rural tourism, and various fruit picking tours and lodging have emerged in endlessly. Dai Jun seized this opportunity. In 2020, nearly $200 \mathrm{mu}$ of raspberry bumper harvest made the local people famous. Keep one side of the green mountains and rivers, blooming the city like a year of water, with the garden not only "100 orchards ", but also medicine base, the four seasons are beautiful, and the top of the mountain highfooted wooden house is about to open to the outside world, that open window open scenery, Many people are eager to try.

\section{Suestions for the development of road traffic in Wuyi County to promote rural revitalization}

\subsection{Implementation and improvement of rural transport networks}

Rural revitalization, transportation first[7].Building roads and expanding traffic is a major project that requires a certain amount of manpower, material and financial resources. Therefore, it is necessary to survey the renovated sections before implementation, determine the soil quality and geographical location, and reduce the engineering injury. The municipal government should give priority to the implementation of the strategy of rural revitalization and the top-level design of fund guarantee[8].Introduce corresponding policies to encourage close cooperation between county and township governments and effective counication and cooperation with relevant transport departments.

Reasonable transportation and establishment of good transportation stations. Properly handling the transportation problems in the process of product transportation can effectively reduce the risk of product transportation. The choice of suitable geographical location as a transportation station is the guarantee of transportation to promote rural revitalization. Although from 2014 to 2021, Wuyi County has established 22 public transport hubs with an investment amount of 673.1 billion yuan, it should continue to develop, do a good job in the three-line combination of rural to urban, urban to rural areas, and establish a wider transportation network. 


\subsection{Creating characteristic towns and promoting the economic development of the foreign population}

Wuyi County is a subtropical monsoon climate, not only four seasons, but also known as "hot spring city, fluorite town" reputation. And natural landscape and tourism resources are very rich, has enough attraction to the foreign population. By App, the Internet and other forms, the local government can combine the characteristics of Wuyi Town with rural tourism, rural products and so on, to attract investors to join and promote the development of road traffic. Wuyi County includes 7 towns and 16 townships. In the process of rural landscape planning, it is necessary to scientifically and reasonably plan and design rural landscape according to the specific types of rural landscape, following the principles of planning and design[9].At the same time, it is necessary to combine green construction with beautiful villages and environmental improvement to achieve economic, social and ecological benefits and promote the development of rural revitalization[10].

\subsection{Enhancing awareness of road traffic safety through universal education}

In order to fully implement the work goal of "reducing and controlling" road traffic accidents, further improve the management of rural traffic safety, and prevent and reduce traffic violations and traffic accidents in rural areas from the source[11].In the process of highway construction, the people should carry on the road safety signal light, the traffic law and so on to carry on the effective popularization. Strengthen people's understanding of road safety laws and regulations, let people memorize and master. Avoid unnecessary damage due to lack of knowledge of road safety. Leaders must put road traffic safety management in rural areas in a more important strategic position to help rural revitalization to create a more harmhonious and stable traffic environment[12].

\section{Conclusion}

After studying, this paper draws a conclusion;

- The development of rural revitalization must follow the concept of "want to be rich, build roads first "," highway, Baiye Xing ", adopt the development strategy according to local conditions, vigorously develop transportation, and promote the development of rural revitalization.

- Although traffic development plays a certain role in promoting rural revitalization, there are still some problems in the process of implementation, such as funds, road construction, rural promotion and so on, which require the local government to make an accurate judgment and formulate improvement measures to the current situation.

- The development strategy of transportation to promote rural revitalization is a strategy that Wuyi County can promote the economic development of Wuyi County more accurately and efficiently.

\section{Acknowledgments}

I would like to thank the Ordos Institute of Technology for its strong support for the research project of "Wuyi County Road Traffic Leading Rural Revitalization Practice Based on the Quality of Life Evaluation Index", and thank the team members for their hard work in the road traffic project and the hard work of the instructor.

\section{References}

1. W.X..H, J. W.B, L.G.Y, W.W.Q. A Study on the Design Concept and Application of Traffic-led Rural Revitalization and Development in Jintang County [J]. Sichuan cement 2019 (08):335.

2. L.L, W.X.H, J.W.B, L.G.Y, W.W.Q. Application and Suestions of Road Traffic Leading Rural Revitalization in Jintang County, Chengdu City [J].].1 Sichuan Building Materials ,2020,46 (04):154155 .

3. J.L, L.C.Q An Analysis of the Balanced Relationship between Transport Development and Regional Economic Growth in Zhejiang Province [J].10 Transport Technology and Economics 15 (01): 125128.

4. C.H.B. [J]. Implementation of the Strategy for Rural Transport and Rural Revitalization Zhixing Tongren 2018 (Z1):173-177.

5. W.Y.X. A Study on the Countermeasures of Ecoagriural Tourism Development in the Context of Rural Revitalization [J]. Southern agriure ,2020,14 (20):103-105.

6. L.Q.Y. A Study on Optimization of the Index System of Rural Infrastructure Construction in Central Anhui Province [D].] under the Background of Rural Revitalization Hefei University of Technology ,2020.

7. H.Z.L, H.Z.J. A Study on Management Measures for Safe Operation of Rural Highway [J]. Journal of Guangdong Jiaotong Vocational and Technical College 18 (04): 48-51+58.

8. C.H.B. [J] Implementation of the Strategy for Rural Transport and Rural Revitalization Zhixing Tongren 2018 (Z1): 173-177.

9. M.G.M, J.W.W Discussion on Rural Landscape Planning and Design in the Context of Beautiful Rural Construction [J].and Modern Hortiure, 2019(20): 85

10. The editorial department of this journal. [J].Paving a Safe Road for Rural Revitalization Road Traffic Management, 2020 (07): 52.

11. Z.X. Creating a New Approach to Traffic Safety Management in Rural Areas Automotive and Safety, 2019 (12): 32-34.

12. W.X.H, J.W.B, L.G.Y, W.W.Q. A Study on the Design Concept and Application of Traffic-led Rural 
Revitalization and Development in Jintang County [J]. Sichuan cement 2019 (08): 335. 